\begin{tabular}{|c|c|}
\hline Title & THE MOST FAVORED NATION CLAUSE \\
\hline \multicolumn{2}{|l|}{ Sub Title } \\
\hline Author & 竹森，俊平(TAKEMORI, Shumpei) \\
\hline Publisher & Keio Economic Society, Keio University \\
\hline Publication year & 1994 \\
\hline Jtitle & Keio economic studies Vol.31, No.1 (1994. ) ,p.37- 50 \\
\hline \multicolumn{2}{|r|}{ 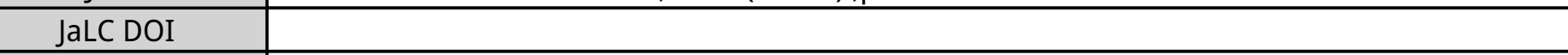 } \\
\hline Abstract & $\begin{array}{l}\text { The paper analyses the implications of the Most Favored Nation Clause in the framework of two- } \\
\text { commodity, three-country model, where each country pursues the maximization of its welfare } \\
\text { using tariffs as instruments. The paper shows that, paradoxically a country can be better off by } \\
\text { renouncing its freedom to choose discriminatory tariffs, because such an action may create a } \\
\text { more favorable Nash equilibrium of tariffs. The paper also contradicts the standard presumption } \\
\text { that the existence of the Most Favored Nation Clause is beneficial for the world economy. }\end{array}$ \\
\hline \multicolumn{2}{|r|}{ (2) } \\
\hline Genre & Journal Article \\
\hline URL & $\begin{array}{l}\text { https://koara.lib.keio.ac.jp/xoonips/modules/xoonips/detail.php?koara_id=AA00260492-1994000 } \\
\text { 1-0037 }\end{array}$ \\
\hline
\end{tabular}

慶應義塾大学学術情報リポジトリ(KOARA)に掲載されているコンテンツの著作権は、それぞれの著作者、学会または出版社/発行者に帰属し、その権利は著作権法によって 保護されています。引用にあたっては、著作権法を遵守してご利用ください。

The copyrights of content available on the KeiO Associated Repository of Academic resources (KOARA) belong to the respective authors, academic societies, or publishers/issuers, and these rights are protected by the Japanese Copyright Act. When quoting the content, please follow the Japanese copyright act. 


\title{
THE MOST FAVORED NATION CLAUSE
}

\author{
Shumpei TAKEMORI*
}

\begin{abstract}
The paper analyses the implications of the Most Favored Nation Clause in the framework of two-commodity, three-country model, where each country pursues the maximization of its welfare using tariffs as instruments. The paper shows that, paradoxically a country can be better off by renouncing its freedom to choose discriminatory tariffs, because such an action may create a more favorable Nash equilibrium of tariffs. The paper also contradicts the standard presumption that the existence of the Most Favored Nation Clause is beneficial for the world economy.
\end{abstract}

JEL classification: (F13) Commercial Policy; Protection; Promotion; Trade Negotiation.

\section{INTRODUCTION}

The idea of the Nash equilibria of bilateral tariff setting game is introduced by the classical paper of Johnson (1953-54). It is further discussed by Mayer (1981) and extended to the three country case by Riezman (1985). Following this line of investigation, the present paper introduces an institutional constraint, the Most Favored Nation Clause (MFNC), in the framework of three-countries tariff setting game and studies its implications.

The model which is set up for the purpose retains only the minimum essentials. Specifically, the numbers of countries and commodities are smallest to study the question of MFNC. In order to study the implications of a restriction on triff discrimination, a model must incorporate at least one country which has two trade partners; the minimum number of countries is therefore three. On the other hand, the minimum number of commodities to be incroporated in a trade model is naturally two. If we assume the combination of these numbers, it results that there exists only one country which has two trade partners. For, if Country A exports commodity $\# 1$ to Countries $\mathrm{B}$ and $\mathrm{C}$, in exchange for commodity $\# 2$, Country $\mathrm{B}$ can export neither commodity $\# 1$ nor commodity $\# 2$ to Country $C$ and vice versa. We name this country with two trade partners as the home country and focus our attention on its strategic choices; the MFNC, which rules out discriminatory

* I am grateful to Eric Bond, Fumio Dei, Ron Jones, Steve Easton, Sugata Marjit, Wolfgang Mayer, Michihiro Ohyama, and Makoto Yano for helpful comments. The study is stimulated by a suggestion made by Walter Oi. All remaining errors are mine.

The request for the proofs and the reprint of the paper should be made: Department of Economics, Keio University, Mita 2-15-45, Minato-ku, Tokyo 108, Japan. 
tariffs, primarily affects the home country in its choces of tariff rates against trade partners.

Two-stage game is played in the following sequence. In the first stage, the home country chooses whether or not to commit to the MFNC. By choosing to commit to the MFNC, the home country voluntarily restricts its own scope of actions because the MFNC rules out a choice of different tariff rates vis-a-vis the two trade partners. The actual choices of tariff rates are made by three countries in the second stage, where the three countries are assumned to take Nash strategies. Specifically, they choose their respective real income maximizing tariffs (optimal tariffs), given the tariff rates chosen by other countries and the choice of the home country at the first stage.

If the home country chooses to commit to the MFNC in the first stage, the Nash equilibrium of the second stage will be different from the one which will be realized if it chooses not to commit. By comparing the first type of equilibrium with the second, we derive the main conclusions: First, the home country may be better off by committing to the MFNC in the first stage. This somewhat paradoxical result arises because the home country's choice in the first stage alters the optimum response of other countries. Therefore, the home's action which, in the absence of the responses by other parties, hurts itself may actually improve its welfare by inducing desirable responses of other parties under the altered condition of the game. Second, the world welfare may be greater under discriminatory tariffs than with the MFNC. Again the home's renunciation of its right to discriminate benefits the world in the absence of responses by other parties. The MFNC may not be desirable for the world precisely because of these responses.

There is a basic message in these propositions: When there are responses of other parties, the effects of a player's action are quite different from when there are no such responses. The idea has an echo of the theory of second-best. It is also shared by several important studies in the field of industrial organization. In Dixit (1980), for example, an incumbent firm of an industry overinvests at the first stage on purpose, in order to force itself into more aggressive behavior visa-vis an entrant at the second stage; the overinvestment by the incumbent can be justified on account of the reaction by the entrant. A similar strategy is present in the $R \& D$ competition of Brander and Spencer (1983). In their setting, two rival firms overinvest in $R \& D$ at the first-stage in the aim of changing favorably the second stage Nash equilibrium. In Cooper (1986), a most favored customer clause which is proclaimed by one frrm is once again a strategic choice, aiming to change the nature of the game; by commiting to a less aggressive behavior, the firm raises its profit as well as the profit of the rival firm in a Bertrand-type competition.

It is without dispute that the most favored nation clause has played a significant role in shaping world trade. In the post-war era, the MFNC has been the principle upon which the GATT is based. But prior to the formation of the GATT, the United States and many European nations had proclaimed the MFNC as the 
guiding principle commercial policy since the 18 th century. ${ }^{1}$ What is the gain which accures to the country if it renounces the right to discriminate? Our result answers to this question; By this act, a country changes the nature of tariff setting game.

Although our paper studies only the outcomes of non-cooperative behaviors by all countries, the tariff warfare case in Mayer's paper, our results also have implications for the study of tariff negotiations, such as the one under the GATT, in which negotiators met with the objectives of adjusting tariffs, such that all countries become at least as well off as thy would be under the tariff warfare. In this setting, the Nash equilibrium of a tariff game becomes a threat point for the subsequent tariff negotiations. (This argument is stressed by Mayer.)

The next section describes our trading world, which consists of three countries and two commodities. The setting is basically similar to the one studied in Caves (1974), which discussed the strategy of one country, neglecting the reactions of the others.

Section 3 characterizes the world Nash equilibrium under the two alternative regimes. The world can be either under the "discriminatory" regime, in which countries are allowed to set discriminatory tariffs or under the "nondiscriminatory" regime, in which they are not allowed to do so.

Section 4 studies the possibility of a paradox: "It is sometimes better for a country unilaterally to renounce its right to discriminate in the matter of tariffs."

Section 5 studies how the world welfare is affected by the MFNC.

\section{THE MODEL}

\section{A. Market Equilibrium}

There are three countries and two commodities in the world. The commodities are named $\mathrm{A}$ and $\mathrm{B}$, and $\mathrm{A}$ will be taken as the numeraire. Country $\mathrm{H}$, or the home Country, is the importer of Commodity A from two countries, named Countries 1 and 2, and it exports Commodity B to its trade partners in exchange. No trade takes place between Countries 1 and 2. (Our assumption on the trade pattern implies that only Country $\mathrm{H}$ has an incentive to exercise discriminatory tariffs, since it alone has two partners to trade with.) For simplicity, we assume that Country $\mathrm{H}$ does not consume any of its export good $\mathrm{B}$ and that it has a well behaved concave production possibility frontier between goods $\mathrm{A}, \mathrm{B}$. We also assume that perfect competition prevails everywhere in the world.

There are four import tariffs to be considered in this model, two tariffs on the import of Commodity B by Countries 1 and 2, and two tariffs on the import of Commodity A by Country $\mathrm{H}$. These tariffs create wedges between various consumer and producer prices.

Let us define the notations as follows.

\footnotetext{
1 See Viner (1924) for the history of the MFNC prior to the formation of GATT.
} 
$t_{j}$ the tariff by Country $\mathrm{H}$ on the import of Commodity A from Country $j . \quad(j=1,2$.

$t_{j}^{*} \quad$ the tariff by Country $j$ on the import of Commodity B.

$P^{A}, P^{B}$ the (nominal) domestic prices of Commodities A, B in Country $\mathrm{H}$.

$P_{j}^{A}$ the (nominal) prices that Countries $j$ charge on the exports to Country $\mathrm{H}$. We assume that $t_{1}^{*}, t_{2}^{*}$ represents standard ad-valorem tax rates. However, we define tax rates $t_{1}, t_{2}$ implicitly as in (1), since this specification simplifies the algebra in the later sections. ${ }^{2}$

$$
P^{A}=\frac{1}{\left(1-t_{j}\right)} P_{j}^{A}, \quad(j=1,2 .)
$$

It is also more convenient to base our discussions on the relative prices. Let

$$
\begin{array}{cl}
P_{j}=P^{B} / P_{j}^{A} & \text { the supply price of Country } \mathrm{H} \text { vis-a-vis Country } j . \quad(j=1,2 .) \\
P=P^{B} / P^{A} & \text { the relative domestic price in Country } \mathrm{H} .
\end{array}
$$

From (1), $P$ is related to $P_{1}, P_{2}$, by

$$
P=\left(1-t_{j}\right) P_{j}, \quad(j=1,2 .)
$$

Due to the presence of import tariffs by Countries 1 and 2, $P_{1}$ and $P_{2}$ are not the relative domestic prices in Countries 1 and $2 .^{3}$ When the MFNC is enforced, $t_{1}$ and $t_{2}$ must be set equal. Then from (2), $P_{1}$ and $P_{2}$ will also be equal. We denote by $t$, the common import tariff by Country $\mathrm{H}$, and by $P^{*}$, the world price, under this condition.

We can now formulate the equilibrium condition of the world commodity market. Due to the assumption that Country $\mathrm{H}$ consumes none of its export good, the total export by Country $\mathrm{H}$ equals its total production. Under the assumption of the concave production frontier, the supply can be characterized by a single valued and continuously differentiable export supply function; denoting by $X$ the total export supply of Country $\mathrm{H}$

$$
X=X(P) .
$$

2 The relation between tax rates $t_{1}$ and the standard ad-valorem tax rate $t_{1}$, is given by:

$$
\left(1+t_{1}\right)=\frac{1}{1-t_{1}}
$$

3 The relative domestic price in Country 1 , for instance, can be expressed as

$$
\left(1+t_{1}^{*}\right) P_{1}=\frac{\left(1+t_{1}^{*}\right)}{\left(1-t_{1}\right)} P
$$

In order to emphasize the effects of the MFNC, the arbitrage activity is assumed away in our model. One possible explanation for the absence of arbitrage is the ban on such activity by an importer of commodity B. If a country, which imports commodity B, has relatively high elasticity of demand for the good, it gains from the segmentation of the world market for the good. Hence it has a strong incentive to ban arbitrage. The point is studied in Jones and Takemori (1989). 
Its first derivative is assumed to be positive. We define the elasticity of total export supply by

$$
\sigma=\frac{X^{\prime}}{P X}
$$

The import demands by Countries 1 and 2 are formulated as function of the import tariff and the supply price:

$$
\begin{array}{cc}
m_{j}=m_{j}\left[t_{j}^{*}, P_{j}\right] & (j=1,2 .) \\
\text { with } \delta m_{j} / \delta t_{j}^{*}<0, & \delta m_{j} / \delta P_{j}<0 .
\end{array}
$$

By using (2) and (3), we can express the equilibrium condition of the world market as

$$
m_{1}\left[t_{1}^{*}, P /\left(1-t_{1}\right)\right]+m_{2}\left[t_{2}^{*}, P /\left(1-t_{2}\right)\right]=X(P) .
$$

The above equation determines equilibrium domestic price $P$. By differentiating this condition, the percentage change in equilibrium $P$ can be expressed as the function of the changes in $t_{1}, t_{2}, t_{1}^{*}, t_{2}^{*}$,

$$
\hat{P}=\frac{\theta_{1} \varepsilon_{1 t} d t_{1}^{*}+\theta_{2} \varepsilon_{2 t} d t_{2}^{*}+\theta_{1} \varepsilon_{1} d t_{1} /\left(1-t_{1}\right)+\theta_{2} \varepsilon_{2} d t_{2} /\left(1-t_{2}\right)}{\sigma+\theta_{1} \varepsilon_{1}+\theta_{2} \varepsilon_{2}}
$$

where ${ }^{\wedge}$ denotes the percentage change of a variable and

$$
\varepsilon_{j}=-\left(\delta m_{j} / \delta P_{j}\right)\left(P_{j} / m_{j}\right), \quad \varepsilon_{j t}=-\left(\delta m_{j} / \delta t_{j}^{*}\right)\left(1 / m_{j}\right), \quad \theta_{j}=m_{j} / X .
$$

In (5), denominator of the right hand side is positive by our assumptions on $\sigma$, $\varepsilon_{1}, \varepsilon_{2}$. (The stability of the market is then implied.) As is clear from (5), an imposition of any import tariff will lower the relative domestic price. of $\mathbf{B}$ in the home country. We will next consider how the tariffs are chosen by the three countries, when each country wants to maximize its welfare given the choices of the others.

\section{B. Optimum Strategies of the Foreign Countries}

We start by considering the optimum choice of $t_{j}^{*}$ by Country $j$, given $t_{k}^{*}, t_{j}$, $t_{k} \cdot(j=1,2 . j \neq k$. $)$ Using a standard measure, the change in the real income of Country $j, d y_{j}$, is expressed in terms of the changes in the consumption of $\mathbf{A}$ and $\mathrm{B},\left(D_{j}^{A} . D_{j}^{B}\right)$, and the domestic price in Country $j,\left(1+t_{j}^{*}\right) P_{j}$.

$$
d y_{j}=d D_{j}^{A}+\left(1+t_{j}^{*}\right) P_{j} d D_{j}^{B} .
$$

The budget constraint of Country $j$ is given by

$$
D_{j}^{A}+P_{j} D_{j}^{B}=O_{j}^{A}+P_{j} O_{j}^{B}
$$

where $O_{j}^{A}$ and $O_{j}^{B}$ are domestic productions of A and B by Country $j$. Totally differentiating (7), and using domestically valued output maximization condition 
and (6), we obtain:

$$
d y_{j}=-m_{j} d P_{1}+t_{j}^{*} P_{j} d m_{j} .
$$

Hence the real income of Country $j$ is maximidzed at

$$
t_{j}^{*}=\hat{P}_{j} / \hat{m}_{j}
$$

By using the market equilibrium condition and the fact that, given $t_{k}^{*}, t_{j}, t_{k}, \hat{P}_{j}$ is equal to $\hat{P}_{k}$ and $\hat{P}$, we can rewrite the above expression as

$$
t_{j}^{*}=\left[\left(X-m_{k}\right) / \hat{P}\right]^{-1} .
$$

The above equation implies that the optimum tariff must be set equal to the inverse of the elasticity of the excess supply by the rest of the world. This elasticity can be decomposed into the elasticity of the suply by the home country, and the elasticity of the excess demand by Country 2 . After some manipulation, we get:

$$
\tilde{t}_{j}^{*}=\frac{\theta_{j}}{\sigma+\theta_{k} \varepsilon_{k}}, \quad(j=1,2 . j \neq k .)
$$

$\tilde{t}_{j}^{*}$ is the optimum tariff for Country 1 .

\section{Optimum Strategy of the Home Country}

Next we consider the optimum choice of the import tariffs by Country H. Due to the assumption that Country $\mathrm{H}$ does not consume its export good $\mathrm{B}$, the real income of Country $\mathrm{H}$, which will be referred as $y$, is measured by the amount of its consumption of good $\mathrm{A}$, denoted as $D A$.

We will assume that the MFNC effectively constrains Country H's policy; Country $\mathrm{H}$ will set, vis-a-vis Countries 1 and 2, two different import tariffs if the MFNC is not applied and a uniform import tariffs if it is applied. To save space, we henceforth refer to a world as regime $D$ (discriminatory) when the MFNC is not applied, and to be as regime $\mathbf{N}$ (non-discriminatory) when the clause is applied. We must consider separate budget constraints under the two regimes. Under regime $\mathrm{D}$ the budget constraint is

$$
D^{A}=O^{A}+P_{1} m_{1}+P_{2} m_{2} .
$$

Where $O^{A}$ is the domestic production of $\mathrm{A}$ by Country $\mathrm{H}$. Under regime $N$ it is

$$
D^{A}=O^{A}+P^{*} X .
$$

By totally differentiating (10) and the domestically valued output maximization condition we obtain

$$
d y=\left(m_{1} d P_{1}+t_{1} P_{1} d m_{1}\right)+\left(m_{2} d P_{2}+t_{2} P_{2} d m_{2}\right)
$$

Hence the real income of the home country is maximized under regime $D$ at 


$$
\tilde{t}_{j}=-\frac{\hat{P}_{j}}{\hat{m}_{j}}, \quad(j=1,2 .)
$$

Substituting $\hat{m}_{j}=-\varepsilon_{j} \hat{P}_{j}$ in the above equation, we derive the optimum discriminatory tariff as the inverse of the respective country's elasticity of import demand.

$$
\tilde{t}_{j}=\frac{1}{\varepsilon_{j}}, \quad(j=1,2 .)
$$

By similar method, we derive from (11) the optimum uniform tariff:

$$
\tilde{t}=\frac{1}{\theta_{1} \varepsilon_{1}+\theta_{2} \varepsilon_{2}} .
$$

The denominator of (14) is the elasticity of the world import demand.

So far, we have discussed how each country chooses its real income maximizing import tariffs, given the choices by the others. In the next section, we study how these optimum tariffs are simultaneously determined under the Nash equilibria.

\section{THE WORLD NASH EQUILIBRIUM UNDER THE TWO REGIMES}

In this section, we first characterize the world Nash equilibrium under regime D. At this point we have to make some strong assumptions to simplify the analysis: the elasticities $\sigma, \varepsilon_{1}, \varepsilon_{2}$ are assumed to be constant in the subsequent discussions. ${ }^{4}$ Then (13) shows that, under this assumption the optimum discriminatory tariffs of the home Country is constant and independent from the choice of tariffs by the trade partners. (In other words, (13) gives the dominant strategies of the home country.)

The optimum import tariffs of Countries 1 and 2, however, still depend on all other tariffs. By totally differentiating (9) and using $\theta_{1}+\theta_{2}=1, d \theta_{1}+d \theta_{2}=0$, and $d \sigma=0$, we obtain an expression for the change in country $j$ 's optimum tariff.

$$
d t_{j}^{*}=\frac{\sigma+\varepsilon_{k}}{\left(\sigma+\theta_{k} \varepsilon_{k}\right)^{2}} d \theta_{j} \quad(j=1,2 . k \neq j .)
$$

4 The constancy assumptions of $e_{j}$ 's are much more essential to our analysis than that of $s$. (The latter assumption slightly simplifies the algebra.) The former is equivalent to the assumption that the offer curve is constantly elastic. This case is extensively discussed in Johnson (1953-54). In order for the offer curve of Country $j$ to exhibit this property, Country $j$ must have a fixed supply of good $A$ and no supply of good B. Moreover, its preference must be represented by the following quasi-linear utility function.

$$
U_{j}=f\left[D_{j}^{A}+\beta\left(D_{j}^{B}\right)^{\alpha}\right]
$$

where $f[$.$] is an arbitrary monotonically increasing function and \alpha, \beta$ are constant parameters with $1>\alpha>0, \beta>0$. 
(a)

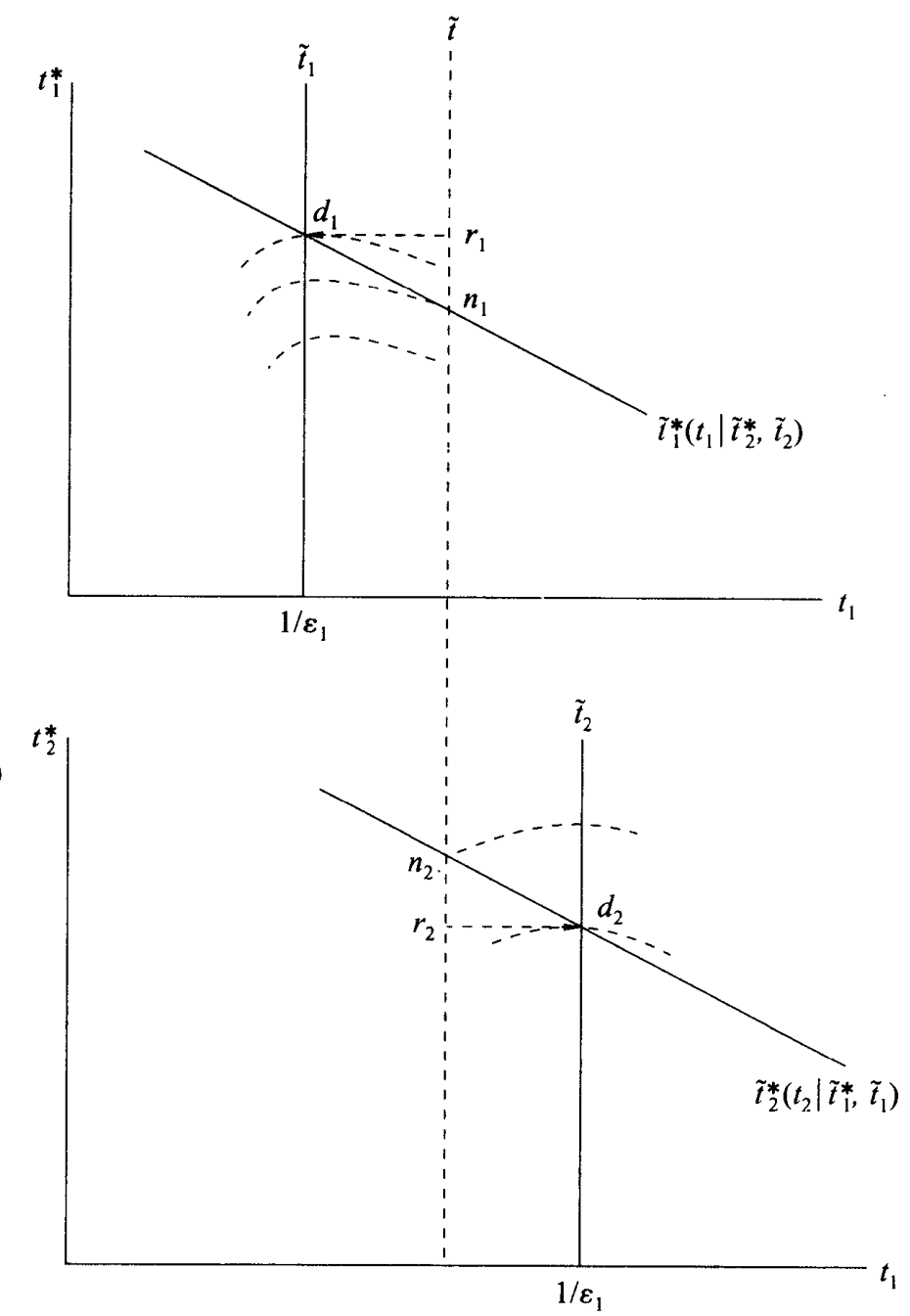

Fig. 1. Reaction Curves (I).

The world Nash equilibrium can be illustrated in diagrams. In Fig. 1-a, the vertical and horizontal axis measure, respectively, $t_{1}$ and $t_{1}^{*}$, whereas Fig. 1-b focuses on $t_{2}$ and $t_{2}^{*}$. The vertical lines $\tilde{t}_{1}$ and $\tilde{t}_{2}$ at the levels $1 / \varepsilon_{1}$ and $1 / \varepsilon_{2}$, in Figs. 1-a and 1-b depict the optimal discriminatory strategies of Country $\mathrm{H}$. On the other hand, the $\tilde{t}_{1}^{*}$ schedule depicts the reaction curve of Country 1 for different levels of $t_{1}$ and given levels of $t_{2}$ and $t_{2}^{*}$. This curve is downward sloping since for, given $t_{2}$ and $t_{2}^{*}$, Country 1's volume of import is smaller with a higher $t_{1}$, hence its share in the world trade is also smaller. Therefore, (15) implies that its optimum import tariff will be lower. The two intersections in Figs. 1-a and 1-b, characterize the world Nash equilibrium, provided that the levels of tariffs in the two diagrams are consistent. Also illustrated in the two diagrams are "iso-real income Curves" of Country $\mathbf{H}$. The curves have peaks at $\tilde{t}_{1}$ and $\tilde{t}_{2}$, and the lower the curve the higher the real income of Country $\mathrm{H}$ it represents. 


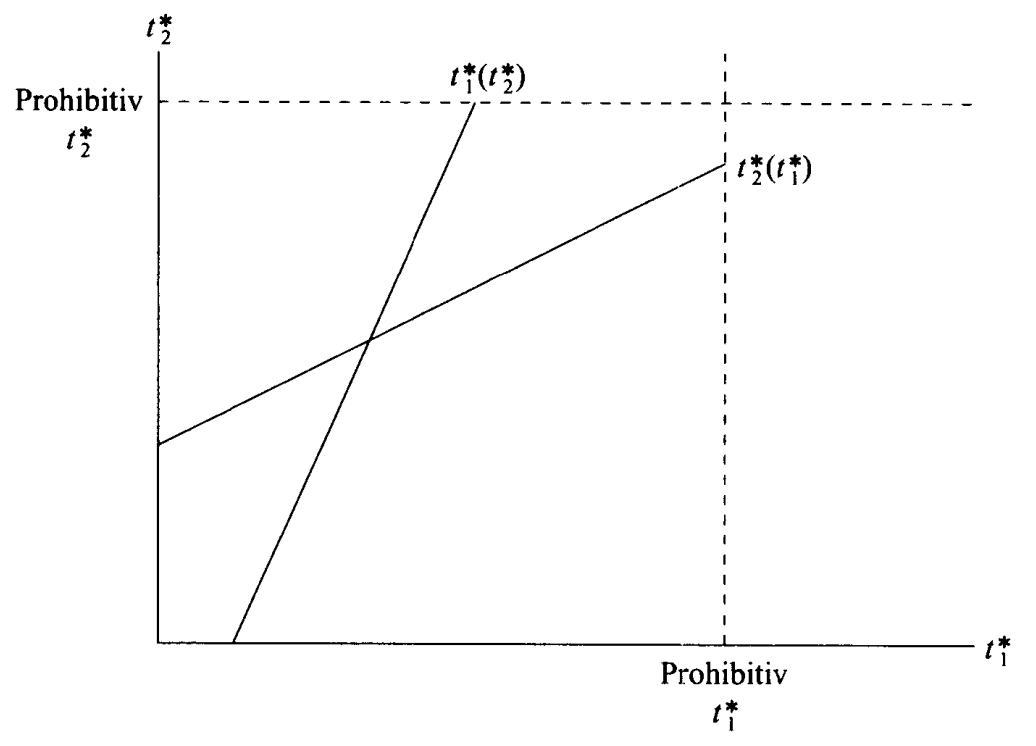

Fig. 2. Reaction Curves (II).

An alternative way of illustrating the world Nash equilibrium is to take only $t_{1}^{*}$ and $t_{2}^{*}$ as arguments, since $\tilde{t}_{1}$ and $\tilde{t}_{2}$ are constant. In Fig. 2, $t_{1}^{*}$ and $t_{2}^{*}$ are drawn, respectively, in horizontal and vertical axis. The $\tilde{t}_{1}^{*}\left(t_{2}^{*}\right)$ locus describes the optimum tariff of Country 1 , given different levels of $t_{2}^{*}$. It is continuously defined between $t_{2}^{*}=0$, and the maximum prohibitive level of $t_{5}^{*},{ }^{2}$ and never slopes downward because a higher $t_{2}^{*}$ implies a smaller volume of imports by Country 2 , and hence a larger import share of Country 1. ((17) then implies that the optimum import tariff of Country 1 is higher.) The optimum tariff of Country 1 never exceeds the maximum prohibitive level, since some trade is always better than no trade. Similarly $\tilde{t}_{2}^{*}\left(t_{1}^{*}\right)$ is the reaction curve of Country 2 which exhibits a positive slope. It is easy to check that the two curves have an intersection under the stated condition. Hence the World Nash equilibrium exists. (We assume the uniqueness of the equilibrium.)

We next characterize the world Nash equilibrium under regime $\mathrm{N}$. The strategy of Country $H$ is illustrated now by the vertical line $\tilde{t}=1 /\left(\theta_{1} \varepsilon_{1}+\theta_{2} \varepsilon_{2}\right)$, going from Fig. 1-a to Fig. 1-b. Naturally the $\tilde{t}$ line passes between $\tilde{t}_{1}$ and $\tilde{t}_{2}$, since the elasticity of the world import demand is the weighted average of the elasticities of the import demand in the two countries. The world Nash equilibrium under regime $N$ is given by the intersection of $\tilde{t}$ with the two reaction curves $\tilde{t}_{1}^{*}$ and $\tilde{t}_{2}^{*} \cdot{ }^{6}$

Figure 1 suggests the following scenario; If the world moves from regime $D$ to regime $\mathrm{N}$, the home tariff vis-a-vis Country 2 is reduced from $\tilde{t}_{2}$ to $\tilde{t}$. In response

\footnotetext{
5 The level of $t_{2}^{*}$ at which the volume of trade by Country 2 shrinks to zero depends on the levels of $t_{1}, t_{2}$, and $t_{1}^{*}$. Here we take simply the maximum value of the prohibitive tariff for Country 2 as the maximum of the domain of the Country l's reaction function.

${ }^{6}$ Between two equilibrium under alternative regimes, the reaction curves $\tilde{t}_{1}^{*}, \tilde{t}_{2}^{*}$ cannot remain unshifted. But in order to convey the basic idea in simpler fashion, we neglect this shift in the diagram.
} 
to this, Country 2 increases its tariff level; the home country's welfare is lowered in its trade with Country 2 both because its tariff is lowered from lthe optimum level and country 2 responds by raising its tariff. In the trade with Country 1, the situation is the opposite: As a result of the increase in the home import tariff from $\tilde{t}_{1}$ to $\tilde{t}$, Country 1 lowers its import tariff. The decrease in the import tariff favorably affects the home country's welfare and if ithis effect dominates the direct loss which results from the home's new choice of the tariff level vis-a-vis Country 1 , then the home country might score a gain in the trade with Country 1 .

Is it possible that the home country's increase in surplus in the trade with Country 1 outweighs its decrease in surplus in the trade with Country 2, so that the MFNC benefits the home country? The next section answers this question.

\section{CAN THE MFNC BENEFITS THE HOME COUNTRY?}

The purpose of this section is to investigate whether a presence of the MFNC can improve the welfare of the home country. To apply an algebraic approach, however, it is more convenient to take regime $\mathrm{N}$ as the benchmark situation; we will see how the shift from regime $\mathrm{N}$ to regime $\mathrm{D}$, due to an abolition of the MFNC, affects the home country's welfare. The shift in regime involves changes in Country H's tariffs. Without a loss of generality, we assume $\varepsilon_{1}>\varepsilon_{2}$, and define

$$
d t_{j}=\tilde{t}_{j}-\tilde{t},(j=1,2 .) \quad \Delta \varepsilon=\varepsilon_{1}-\varepsilon_{2}, \quad \varepsilon=\theta_{1} \varepsilon_{1}+\theta_{2} \varepsilon_{2} .
$$

In order to apply a differential method, we will take the limiting case, $\Delta \varepsilon \rightarrow 0$. (That is, we will discuss only the situation where Countries 1 and 2 are only marginally different in their elasticities of import demand.) From the formulas of the home optimum tariffs, $d t_{j}$ 's are given by:

$$
d t_{j}=-\frac{\theta_{k} \Delta \varepsilon}{\varepsilon_{j} \varepsilon}, \quad(j=1,2 . j \neq k .)
$$

On the other hand by using (10) and noting that

$$
d P_{j}=\frac{1}{\left(1-t_{j}\right)} d P+\frac{P}{\left(1-t_{j}\right)^{2}} d t_{j}
$$

we can express the change in the real income of Country $\mathrm{H}$ which is caused by the shift in regimes from $\mathrm{N}$ to $\mathrm{D}$ as:

$$
\frac{d y}{P^{*} X}=\frac{\theta_{1} d t_{1}+\theta_{2} d t_{2}}{(1-\tilde{t})}+(1+\tilde{t} \sigma) \hat{P}
$$

The first term of the above equation is directly related to the total volume of trade, since $X=X(P)$. (Given a positive price cost margin which is created by tariffs, the home country gain if the production of its export good expands.) The general formula for $\hat{P}$ is given by (5). But when $d t_{1}$ and $d t_{2}$ are substituted from 
(16), the last two terms cancel each other and (5) is reduced to

$$
\hat{P}=-\frac{\theta_{1} \varepsilon_{1 t} d t_{1}^{*}+\theta_{2} \varepsilon_{2 t} d t_{2}^{*}}{\sigma+\varepsilon}
$$

Combining the above two equations together, we obtain:

$$
\frac{d y}{P^{*} X}=\frac{\theta_{1} d t_{1}+\theta_{2} d t_{2}}{(1-\tilde{t})}-\frac{(1+\tilde{t} \sigma)}{\sigma+\varepsilon}\left(\theta_{1} \varepsilon_{1 t} d t_{1}^{*}+\theta_{2} \varepsilon_{2 t} d t_{2}^{*}\right)
$$

The above equation breaks down the overall effects into two components:

(a) The first term which shows the direct effect of the changes in the home country's tariff rates, given the initial levels of foreign tariffs. In Fig. 1, this effect corresponds to the horizontal moves from points $r_{1}, r_{2}$ to points $d_{1}, d_{2}$.

(b) The second term which shows the welfare effects of the foreign countries reactions. This effect works through the change in the trade volume. In Fig. 1, this effect corresponds to the verticall moves from points $n_{1}, n_{2}$ to points $r_{1}, r_{2}$.

By substituting (16) into the above equation, we can check that effect (a) is indeed in favor of the home country.

$$
\frac{d y}{P^{*} X}=\frac{\theta_{1} \theta_{2}}{(1-\tilde{t}) \varepsilon_{1} \varepsilon_{2} \varepsilon}(\Delta \varepsilon)^{2}-\frac{(1+\tilde{t} \sigma)}{\sigma+\varepsilon}\left(\theta_{1} \varepsilon_{1 t} d t_{1}^{*}+\theta_{2} \varepsilon_{2 t} d t_{2}^{*}\right)
$$

Hence the shift to regime D may hurt the home country only through the foreign reactions. Substituting (15) for $d t_{1}^{*}$ and $d t_{2}^{*}$, and rearranging, we obtain:

$$
\begin{gathered}
\left(\theta_{1} \varepsilon_{1 t} d t_{1}^{*}+\theta_{2} \varepsilon_{2 t} d t_{2}^{*}\right)=\psi d \theta_{1} \\
\psi=\frac{\theta_{1} \varepsilon_{1 t}\left(\sigma+\varepsilon_{2}\right)}{\left(\sigma+\theta_{2} \varepsilon_{2}\right)^{2}}-\frac{\theta_{2} \varepsilon_{2 t}\left(\sigma+\varepsilon_{1}\right)}{\left(\sigma+\theta_{1} \varepsilon_{1}\right)^{2}}
\end{gathered}
$$

$d \theta_{1}$ is positive as a result of the shift from regime $\mathrm{N}$ to regime $\mathrm{D}$, since in this move, Country $\mathrm{H}$ reduces its import tariff for Country 1 and increases its import tariff for Country 2. (19) then shows that the net welfare effect of foreign reactions depends on the sign of $\psi$ which can be positive or negative. For instance, if the values of elasticities of the two countries, $\varepsilon_{j}$ and $\varepsilon_{j t}$ are close, then it will be positive if $\theta_{1}$ is close to 1 , and positive if $\theta_{1}$ is close to 1 . The home country loses the shift to regime D (it gains from the MFNC) only if $\psi$ is positive. In other words, The MFNC benefits the home country (The shift to Regime D hurts the home country) if

(i) In the real income expression (17), the foreign reaction effect outweighs the trade redistribution effect ${ }^{7}$ and

\footnotetext{
7 We can make the trade redistribution effect arbitrarily small by choosing $\Delta \varepsilon$ small. This is the case since, by the envelope property, when the difference in the elasticities of the import demand of the two countries is marginal then the trade redistribution effect is also marginal.
} 
(ii) $\theta_{1}$ is far greater than $\theta_{2}$ so that the reaction effect of Country 1 outweighs that of Country 2.

The appendix decompopses (19) into more basic parameters and establishes more rigorously the statement of this section.

\section{THE MFNC AND THE WORLD WELFARE}

In this section, we study how the welfare of the world is affected by the MFNC, taking account of the responses of all parties. First, let us define the measure of the change in the world real income on which our discussion is based. Regime $\mathbf{N}$ is once again taken as the benchmark, and we define the change in the world real income, $d y_{w}$, which results from the shift to regime $\mathrm{D}$, as the sum of $d y, d y_{1}, d y_{2}{ }^{8}$ From (6) and (12), we obtain:

$$
d y_{w}=P^{*}\left(\tilde{t}_{1} d m_{1}+\tilde{t}_{2} d m_{2}\right)+\tilde{t} P^{*} d X
$$

By rearranging, we get:

$$
d y_{w}=\left(\tilde{t}_{1}-\tilde{t}_{2}\right) d m_{1}+\left(\tilde{t}_{2}+\tilde{t}\right) d X
$$

The above equation breaks down the overall welfare effects into two components: the price differential effect, which is captured in the first term and the volume of trade effect, which is captured in the second term. This decomposition is familiar in the literature of price discrimination theory. (See Schmalensee (81), for example.)

We already know that $d X$ can positive or negative from the analysis of the last section. (In the literature of price discrimination theory, this effect is usually assumed to be neutral.) We also know that $d m_{1}$ is positive, since in its shift from Regime $\mathrm{N}$ to Regime $\mathrm{D}$, the home country lowers the tariff vis-a-vis Country 1 , which has a higher elasticity of demand. Hence remarkably, the question of whether the world is more likely to gain from the tariff discrimination or not, boils down to the comparison of foreign tariffs: Whether $\tilde{t}_{1}$ is greater than $\tilde{t}_{2}$, or not?

It is quite plausible that $\tilde{t}_{1}$ is greater than $\tilde{t}_{2}$, so that the shift to Regime $\mathrm{D}$ improves the world welfare. For example, if $\theta_{1}=\theta_{2}$, the two country's market size are equal, we see from (9) that

$$
\operatorname{sgn}\left(\tilde{t}_{1}-\tilde{t}_{2}\right)=\operatorname{sgn}\left(\varepsilon_{1}-\varepsilon_{2}\right)>0 \text {. }
$$

Hence the shift to Regime D is more likely to improve the world welfare.

Our argument has naturally the second-best perspective. Since the tariff rates that different countries set on the same commodity are different, the home country's tariff discrimination may not necessarily widen the domestic price differentials in the world. Unless it is combined an effort to eliminate the differences

\footnotetext{
$8 d y_{w}$ is an appropriate measure to evaluate the world's gain or loss since if it is positive, then there exists a transfer scheme of Commodity A between the three countries which makes everybody better off.
} 
in the tariff structures of countries, as it is certainly done under the GATT, the MFNC alone may not ensure the improvement of the world welfare.

\section{CONCLUDING REMARKS}

Our analysis clarified the second-best nature of the Most Favored Nation Clause: The tariff discrimination by a country is only one of several distortions. It has also shown that if the responses of other parties which it induces are taken into account, a country's act to renounce its freedom over the commercial policy may not actually be what it looks like; an act of self sacrifice.

The whole arguments hinges on the assumption that a country can commit to the MFNC, but not to its actual tariff levels. The existence of a formal international organization like the GATT, or the acts by prewar western government to proclaim the MFNC as its commercial policy principle, makes reneging the MFNC more difficult than reneging of the actual tariff levels.

The model is best fitted to a real world situation in which the supply of a particular commodity is almost monopolized by a country. By changing the number of countries, or by changing trade patterns, the conclusions are significantly altered. The results of the present paper nevertheless tell that an explicit modelling of the world economy is necessary in order to judge the desirability of the most favored nation clause.

\section{APPENDIX}

In this appendix, we establish more rigorously the conclusion of section 4 , that the application of the MFNC can improve the home country's welfare. (17) and (19) express the change in $P$ as a function of the change in $\theta_{1}$. However, $d \theta_{1}$ can be expressed as

$$
d \theta_{1}=\theta_{1}\left(\hat{m}_{1}-\hat{X}\right)
$$

where $\hat{m}_{1}$ and $\hat{X}$ can be, in turn, expressed as

$$
\begin{gathered}
\hat{m}_{1}=-\varepsilon_{1 t} d t_{1}^{*}-\varepsilon_{1}\left[\hat{P}+d t_{1} /(1-\hat{t})\right] \\
\hat{X}=\sigma \hat{P}
\end{gathered}
$$

By substituting the above expression into (A-1) and rearranging we obtain

$$
d \theta_{1}=-\frac{\theta_{1}\left[\left(\sigma+\varepsilon_{1}\right) \hat{P}+\varepsilon_{1} d t_{1} /(1-\tilde{t})\right]}{1+\varepsilon_{1 t}\left(\sigma+\theta_{2} \varepsilon_{2}\right)^{2}}
$$

We can now substitute (A-2) into (17) and solve for $\hat{P}$.

$$
\hat{P}=\frac{-\psi \varepsilon_{2} \Delta \varepsilon}{(\varepsilon-1)\left[(\sigma+\varepsilon)\left(1+\varepsilon_{1 t}\right)\left(\sigma+\varepsilon_{2}\right) /\left(\sigma+\theta_{2} \varepsilon_{2}\right)^{2}+\theta_{1}\left(\sigma+\varepsilon_{1}\right) \psi\right]}
$$


It can be checked that $\hat{P}$ has the same sign as $-\psi$. By substituting (A-3) into (16) and rearranging we finally obtain

$$
\operatorname{sgn}(d y)=\operatorname{sgn}\left[-g(\psi)+\left(\frac{\theta_{1}}{\varepsilon_{1} \varepsilon_{2}}\right) \Delta \varepsilon\right]
$$

where $g(\psi)$ is the some real number whose sign is the same as the sign of $\psi$ and the second term in the bracket can be made arbitrary small by taking $\Delta \varepsilon$ small. Hence we may have $d y$ negative as is claimed in section 4 .

Keio University

\section{REFERENCES}

Brander, J. A. and B. A. Spencer (1983), "International R \& D Rivalry and Industrial Strategy", Review of Economic Studies, 707-722.

Caves, R. (1974), "The Economics of Reciprocity; Theory and Evidence of Bilateral Trading Agreements", in International Trade and Finance, Essays in Honor of Jan Tinbergen (W. Sellekaerts, ed.), White Plains, NY.

Cooper, T. M. (1986), “Most-Favored-Customer Pricing and Tacit Collusion”, Rand Journal of Economic, 17(3), 377-388.

Dixit, A. (1980), “The Role of Investment in Entry Deterrence”, Economic Journal, 90, 95-106.

Jonson, H. G. (1953-54), "Optimum Tariffs and Retaliation", Review of Economic Studies, 21(2), $142-153$.

Jones R. W. and S. Takemori (1989), "Foreign Monopoly and Optimal Tariffs for the Small Open Economy", forthcoming in European Economic Review.

Mayer, W. (1981), "Theoretical Considerations on Negotiated Tariff Adjustment”, Oxford Economic Papers, 33, 135-153.

Riezman, Re (1985), "Customs Union and the Core", Journal of International Economics, $19,355-365$.

Scmalensee, R. (1981), "Output and Welfare Implications of Monopolistic Third-Degree Price Discrimination", American Economic Review, 71, 242-247. 